\title{
Large herbivores may alter vegetation structure of semi-arid savannas through soil nutrient mediation
}

\author{
Cornelis van der Waal • Ada Kool $\cdot$ Seline S. Meijer · Edward Kohi • \\ Ignas M. A. Heitkönig · Willem F. de Boer · Frank van Langevelde • \\ Rina C. Grant • Mike J. S. Peel · Rob Slotow $\cdot$ Henrik J. de Knegt • \\ Herbert H. T. Prins $\cdot$ Hans de Kroon
}

Received: 5 May 2010/Accepted: 23 December 2010/Published online: 12 January 2011

(C) The Author(s) 2011. This article is published with open access at Springerlink.com

\begin{abstract}
In savannas, the tree-grass balance is governed by water, nutrients, fire and herbivory, and their interactions. We studied the hypothesis that herbivores indirectly affect vegetation structure by changing the availability of soil nutrients, which, in turn, alters the competition between trees and grasses. Nine abandoned livestock holding-pen areas (kraals), enriched by dung and urine, were contrasted with nearby control sites in a semi-arid savanna. About 40 years after abandonment, kraal sites still showed high soil concentrations of inorganic N,
\end{abstract}

Communicated by Jason Kaye.

In cooperation with: N. M. Knox, A. K. Skidmore, E. Mwakiwa, Y. Pretorius, S. E. van Wieren.

C. van der Waal, A. Kool, and S. S. Meijer authors contributed equally.

C. van der Waal · A. Kool - S. S. Meijer · E. Kohi ·

I. M. A. Heitkönig · W. F. de Boer · F. van Langevelde .

H. J. de Knegt · H. H. T. Prins

Resource Ecology Group, Wageningen University,

Droevendaalsesteeg 3a, 6708 PB Wageningen,

The Netherlands

S. S. Meijer

UCD Forestry, Agriculture \& Food Science Centre,

University College Dublin, Belfield, Dublin 4, Ireland

S. S. Meijer

World Agroforestry Centre, Nairobi, Kenya

R. C. Grant

Scientific Services, Kruger National Park, Private Bag X402,

Skukuza 1350, South Africa

M. J. S. Peel

Agricultural Research Council-Range and Forage Institute,

PO Box 13054, Nelspruit 1200, South Africa

extractable P, K, Ca and Mg compared to controls. Kraals also had a high plant production potential and offered high quality forage. The intense grazing and high herbivore dung and urine deposition rates in kraals fit the accelerated nutrient cycling model described for fertile systems elsewhere. Data of a concurrent experiment also showed that bush-cleared patches resulted in an increase in impala dung deposition, probably because impala preferred open sites to avoid predation. Kraal sites had very low tree densities compared to control sites, thus the high impala dung deposition rates here may be in part driven by the open structure of kraal sites, which may explain the persistence of nutrients in kraals. Experiments indicated that tree seedlings were increasingly constrained when competing with grasses under fertile conditions, which might explain the low tree recruitment observed in kraals. In conclusion, large herbivores may indirectly keep existing nutrient

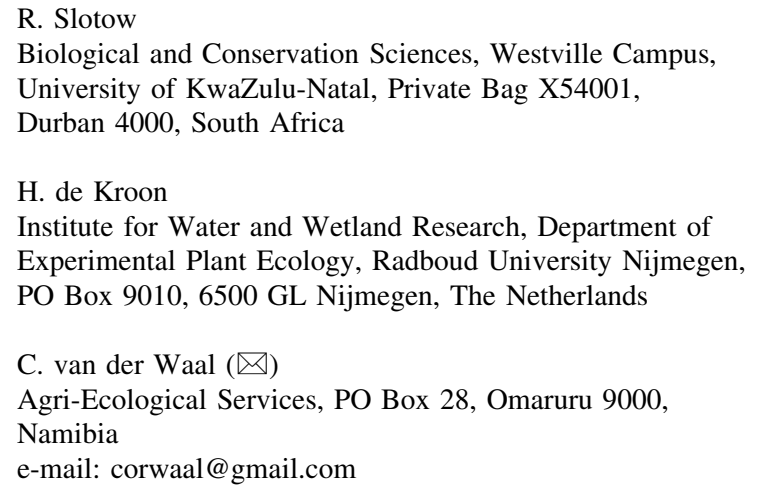


hotspots such as abandoned kraals structurally open by maintaining a high local soil fertility, which, in turn, constrains woody recruitment in a negative feedback loop. The maintenance of nutrient hotspots such as abandoned kraals by herbivores contributes to the structural heterogeneity of nutrient-poor savanna vegetation.

Keywords Bush encroachment · Tree-grass competition $\cdot$ Nutrient hotspot $\cdot$ Seedling $\cdot$ Predation

\section{Introduction}

An important theme in savanna ecology is how resources, such as water and nutrients, and disturbances, such as fire and herbivory, determine the structure of the vegetation, i.e., the balance between woody and herbaceous biomass (Scholes and Archer 1997; Sankaran et al. 2004, 2005, 2008). Variation in the tree-grass balance largely determines savanna functioning, because it affects animal production and shapes animal assemblages (Scholes and Archer 1997; Sankaran et al. 2004, 2005). Direct effects of large herbivores (hereafter herbivores) on savanna structure (e.g., browsers decreasing woody cover) are well documented (Scholes and Archer 1997; van Langevelde et al. 2003). Indirect effects of herbivores, such as herbivores reducing grass fuel loads which in turn suppresses the impact of fire on the tree layer (van Langevelde et al. 2003; Holdo et al. 2007; but see Hanan et al. 2008), are less well studied in spite of their potential to influence savanna structure (Waldram et al. 2008). Similarly, herbivores may change the availability of soil nutrients, which, in turn, alter the competitive balance between functionally different growth forms (Wilson and Tilman 1993; Bokdam 2001). Such an indirect effect has to our knowledge not yet been demonstrated for trees and grasses in savanna-grassland systems. This is in spite of reports of strong herbivore effects on local soil nutrient availability (Augustine et al. 2003) and significant correlations of woody cover with soil nutrient availability (Sankaran et al. 2008). In this paper, we address the question whether the effects of large herbivores on soil nutrient availability affect the tree-grass balance in a semi-arid savanna.

Large herbivores alter soil nutrient availability for plants through changes in soil nutrient cycling rates and spatial redistribution of soil nutrients (Ritchie et al. 1998; Bardgett and Wardle 2003). In a comprehensive review, Bardgett and Wardle (2003) concluded that differences in soil fertility determine the direction of nutrient-mediated herbivore effects on nutrient cycling rates and plant productivity; positive net effects occur under fertile soil conditions and negative net effects under infertile soil conditions. Enhanced local nutrient cycling mediated by large herbivores has been invoked to explain the formation and maintenance of grazing lawns in African savannas (McNaughton et al. 1997). In addition, animals spatially redistribute nutrients if they take in nutrients in one area but excrete nutrients in resting or sleeping areas (Singer and Schoenecker 2003; Moe and Wegge 2008). Substantial amounts of nutrients can be redistributed by large herbivores in this way (Jewell et al. 2007). In a modeling study, de Mazancourt et al. (1998) showed that, although enhanced nutrient cycling contributes to increased nutrient availability in the short-term, a net import of nutrients is crucial for the long-term maintenance of nutrient-rich, productive grazing areas. In Laikipia, Kenya, Augustine et al. (2003) found that impala were responsible for a net influx of nutrients into abandoned livestock holding-pen areas, as they deposited more nutrients than were consumed and exported. Augustine (2004) suggested that this was the result of anti-predator behaviour of impala that preferred the treeless abandoned sites. These patches offered improved visibility in the generally wooded study area (Augustine 2004) and probably improved vigilance against predators (Riginos and Grace 2008).

There are various hypotheses regarding the effects of nutrient availability on woody recruitment in arid savanna and grassland systems. For example, Schlesinger et al. (1996) claim that tree recruitment is enhanced in so-called 'islands of fertility'. In support, Gillson and Ekblom (2009) suggest that an increase in nitrogen availability resulted in an increase in woody vegetation in the Kruger National Park, South Africa. Heisler et al. (2004) did not find any effect of nitrogen availability on shrub expansion, while Sankaran et al. (2008) found in a meta-analysis that tree cover was negatively correlated with soil $\mathrm{N}$ availability in African savannas. As a mechanism explaining the latter relationship, it has been proposed that co-existing grasses increasingly outcompete woody seedlings under fertile conditions, which feed back to a more open vegetation structure in fertile areas (Sankaran et al. 2008; Augustine and McNaughton 2004). There is experimental evidence supporting this hypothesis (Kraaij and Ward 2006; van der Waal et al. 2009). Whichever is correct, herbivore-mediated changes in soil nutrients may influence the structure of savanna vegetation, which, if tree recruitment is constrained in fertile areas, may attract further nutrient imports by herbivores preferring open patches in a positive feedback loop. To our knowledge, a link between savanna vegetation structure and nutrient redistribution by wild herbivores has not yet been demonstrated, but may be an important mechanism maintaining spatial heterogeneity in savanna systems (Blackmore et al. 1990; Augustine and McNaughton 2004).

To address these issues, we studied a 'natural' experiment in a semi-arid savanna, where commercial livestock 
(mainly cattle) ranching was practiced from the early $1900 \mathrm{~s}$ until about 1970 . Since then, wildlife has been the dominant land-use form. During the livestock era, livestock were kept in enclosures (known as 'kraals' in South Africa; 'bomas' in East Africa) at night to safeguard the animals against predation and theft. The outcome was that nutrients accumulated in kraals as a result of the high deposition of nutrients (taken up while grazing during the day) in the form of dung and urine (Blackmore et al. 1990; Augustine 2003). After the change in land-use, the former kraal sites remained as nutrient hotspots in the landscape (Blackmore et al. 1990; Augustine 2003). In this paper, we compare the current soil nutrient status and vegetation structure of kraal sites with nearby control sites located in the surrounding landscape. The main objectives were to test (1) whether the effects of nutrient enrichment created by large herbivores (managed livestock) were still detectable in the soil and vegetation decades after abandonment; (2) if this higher nutrient status feeds back to enhanced vegetation productivity, forage quality and herbivore use, which characterize enhanced nutrient cycling in other systems (Bardgett and Wardle 2003); (3) if the clearing of the woody component that obstructs visibility influences nutrient redistribution by herbivores such as impala, which may explain the maintenance of high nutrient concentrations in kraals if these prove to remain structurally open over time (Blackmore et al. 1990; Augustine 2004); (4) if woody plants have invaded kraal sites after these were abandoned; and (5) if the competitive effect of grasses on tree seedlings increases under fertile conditions as hypothesized by Sankaran et al. (2008). Lastly, we propose a conceptual diagram on the interplay between nutrient availability, tree-grass competition and herbivores to integrate these results and to explain how the vegetation structure of abandoned kraals may be maintained in savannas.

\section{Materials and methods}

Study area and selection of study sites

The study was carried out in the Associated Private Nature Reserve (APNR), consisting of the Timbavati, Klaserie, and Umbabat Private Nature Reserves and the Balule Nature Reserve $\left(24^{\circ} 03^{\prime}-24^{\circ} 33^{\prime} \mathrm{S}, 31^{\circ} 02^{\prime}-31^{\circ} 29^{\prime} \mathrm{E}\right)$, which covers an area of more than $1,700 \mathrm{~km}^{2}$. The APNR is situated in the South African Lowveld, and abuts the Kruger National Park (KNP) in the east. In the APNR, commercial livestock farming (mainly cattle) was widely practiced during the first half of the twentieth century, but proved uneconomical due to poor market access, predator problems (mainly lion), and the high prevalence of tick-borne diseases. Around 1970, livestock ranching was finally abandoned and wildlife-related enterprises became the dominant land-use form. Game fences separating individual reserves and the KNP were removed by 1993, enabling wildlife to move freely between the conservation areas (Bigalke 2000). Large herbivore species occurring in the APNR includes African elephant Loxodonta africana, giraffe Giraffa camelopardalis, African buffalo Syncerus caffer, zebra Equus burchelli, blue wildebeest Connochaetes taurinus, kudu Tragelaphus strepsiceros, waterbuck Kobus ellipsiprymnus and impala Aepyceros melamphus. Predators include lion Panthera leo, leopard Panthera pardus and spotted hyena Crocuta crocuta. Soils in the APNR are mainly derived from weathered granite and gneiss (Venter et al. 2003), and the availability of nutrients such as $\mathrm{N}$ and $\mathrm{P}$ are generally low (Treydte et al. 2007), but heterogeneously distributed in the landscape (Grant and Scholes 2006; Treydte et al. 2007). In the study area, the mean annual precipitation ranges between 450 and $600 \mathrm{~mm}$. A well-developed woody layer includes species such as Sclerocarya birrea, Acacia nigrescens, Combretum apiculatum and Colophospermum mopane. The herbaceous layer includes grass species such as Urochloa mosambicensis, Bothriochloa radicans, Digitaria eriantha, Panicum maximum, Heteropogon contortus and a wide variety of forb species. Fires in the APNR are controlled and generally exceed a fire return period of 3 years. Plant nomenclature follows Gibbs Russell et al. (1990) for grasses and Coates Palgrave et al. (2002) for trees. Mammal nomenclature follows Kingdon (1997).

Nine deserted kraal sites with paired controls were selected in the APNR. Kraal sites (10-30 m diameter) were identified in the field by residents with knowledge of the layout of former farming infrastructures. The presence of old fencing material such as fencing posts and wire confirmed the locations of these former kraal sites. The midpoints of control sites were located at a 200-m distance from kraal midpoints, and were chosen at the same topographical position in the landscape as kraal sites to minimize the confounding effect of topography on kraalcontrol comparisons. The study was conducted during the wet season from November 2006 to March 2007.

Soil collection and analyses

To contrast the fertility of kraal soils with that of the surrounding soils, we analyzed soils sampled in kraal and control sites. At each site, about $30 \mathrm{~kg}$ of topsoil $(0-15 \mathrm{~cm}$ depth) was collected at six random locations per site, pooled, sieved and thoroughly mixed. Sub-samples were chemically analyzed by the Agricultural Research Council in Nelspruit, using standard procedures (Anonymous 1990). For the analyses, cations were extracted with ammonium acetate, aluminium was extracted with $\mathrm{KCl}$ and 
available $\mathrm{P}$ was determined according to the Bray 1 method. The $\mathrm{pH}$ of soils was measured according to the water method (Anonymous 1990).

The soil nitrogen mineralization rates were determined in only eight kraal-control pairs over a 28-day period in the wet season. We used a field incubation method to quantify the in situ net $\mathrm{N}$ mineralization rate (Robertson et al. 1999; Grant and Scholes 2006; Coetsee et al. 2008). For this purpose, six stainless steel pipes (length $15 \mathrm{~cm}$, diameter $5 \mathrm{~cm}$ ) were implanted per site so that $10 \mathrm{~cm}$ of the pipe length was buried. The pipe tops were covered and an aboveground side hole allowed gas exchange. Net mineralization rates were calculated as the difference between nitrate and ammonium concentrations at the start and end of the incubation period, after correcting for soil moisture (Robertson et al. 1999; Coetsee et al. 2008). Start-incubation soil samples were taken within $30 \mathrm{~cm}$ radius of implanted incubation pipes. Soil samples were pooled per site and $10 \mathrm{~g}$ sub-samples, contained in plastic bags, were kept on ice until extraction with $\mathrm{KCl}$ (Robertson et al. 1999; Coetsee et al. 2008). Extracts were analyzed for nitrate and ammonium concentration by the Institute for Soil, Climate and Water of the Agricultural Research Council, Pretoria (Coetsee et al. 2008). The texture of soil sub-samples was determined following Sammis (1996).

A bioassay with maize Zea mays was carried out to validate the findings of the soil chemical analysis. Soil subsamples from kraal $(n=9)$ and control sites $(n=9)$, were contained in nursery bags, and five maize seeds (commercial supply) were planted per bag. The maize plants were kept in a nursery and rainfall was supplemented with frequent watering. After 2 months, the aboveground biomass was harvested, dried $\left(70^{\circ} \mathrm{C}\right)$ to constant mass and weighed. Aboveground biomass was taken as an indicator of soil nutrient status.

\section{Vegetation biomass and forage quality}

The aboveground herbaceous biomass of kraal and control sites was estimated by taking 100 readings per site with a standard Disc Pasture Meter during February 2007 (Bransby and Tainton 1977; Waldram et al. 2008). We used the disc settling height-herbaceous biomass calibration curve, derived for swards in the KNP, of Zambatis et al. (2006). Herbaceous swards in the study area have similar species composition and biomass as swards in the KNP (10-60 km east).

The woody layer was assessed in $200 \mathrm{~m}^{2}$ plots, or in the case of smaller kraal sites, the largest plot area that fitted into kraal sites (minimum, $60 \mathrm{~m}^{2}$ ). Live woody plants rooted within plots were counted.

To determine if forage quality was higher on kraal sites than on control sites, we analyzed leaf samples of the common grass Urochloa mosambicensis, which occurred on all sites except one control site. Leaf material from a random selection of $U$. mosambicensis tufts were collected on each site, and the samples were dried at $70^{\circ} \mathrm{C}$ and milled through a $1-\mathrm{mm}$ sieve. $\mathrm{N}, \mathrm{P}, \mathrm{Ca}, \mathrm{Mg}, \mathrm{Na}$ and $\mathrm{K}$ concentration were measured with a Skalar San-plus autoanalyzer at the laboratory of the Wageningen University (The Netherlands) after destruction with a mixture of $\mathrm{H}_{2} \mathrm{SO}_{4}$, Se and salicylic acid (Novozamsky et al. 1983).

\section{Herbivore use of kraal sites}

The use of kraal and control sites by large herbivores was assessed by (1) calculating dung accumulation rates in marked plots (Augustine 2003), (2) using exclosure cages to assess consumption (Ydenberg and Prins 1981; McNaughton et al. 1996) and (3) assessing the frequency of herbaceous tuft use (Grant and Scholes 2006). First, dung piles were counted in rectangular plots with the maximum area that fitted within kraal sites $(20 \times 30 \mathrm{~m}$, but depending on kraal area), while a default of $20 \times 50 \mathrm{~m}$ plot size was used for control sites. Dung piles were marked with small painted stones at the beginning of the study period (December 2006). After a 33- to 45-day period, new dung piles (unmarked) were counted per species. The identification of dung was aided by experienced field rangers. Second, $1 \times 1.5 \mathrm{~m}$ exclosures $(n=16$ wire netted cages) were installed in December 2006. After 8 weeks, the herbaceous vegetation in two $0.5 \times 0.5 \mathrm{~m}$ quadrates were clipped close to ground level inside the grazer-protected cage and two quadrates alongside cages (controls). The cuttings from cages and controls were separately pooled, dried and weighed. Third, at each site, we assessed the closest herbaceous plant to 100 points spaced $1 \mathrm{~m}$ apart (two or more parallel transects) for presence or absence of recent grazing signs following Grant and Scholes (2006). Plant utilization was expressed as the percentage of tufts utilized.

\section{Habitat manipulation experiment}

We used data from a concomitant habitat manipulation experiment to test whether impala in the study area respond to changes in vegetation structure alone, without associated changes in grazing quality. As part of a larger experiment, six circular plots (34 $\mathrm{m}$ diameter) were marked in a $500 \times 800 \mathrm{~m}$ closed Mopane woodland in the northern parts of the study area. In May 2007, three of the six plots were cleared of all woody vegetation by cutting stems with a chainsaw close to the ground $(<5 \mathrm{~cm}$ height $)$ and treating stumps with an arboricide. The cut plant material was removed from the plots and scattered in the surrounding area. From June 2007 to January 2009, new impala dung 
piles were recorded bi-monthly and marked as described for kraal sites.

\section{Woody recruitment}

To test the hypothesis that herbaceous competition decreases woody seedling recruitment, we conducted two experiments using the tree species $C$. mopane. This species was chosen because it dominates large parts of the study area and has been implicated as a bush encroacher (Smit 2001; MacGregor and O'Connor 2002). We therefore expected it to be a likely candidate to invade abandoned kraal sites within its distribution range. Also, re-measurement of woody transects originally conducted in 1980 in the study area (Witkowski and O'Connor 1996) revealed that $C$. mopane had significantly increased in density and expanded its distribution range in the study area (G. Roux, unpublished data).

In a field fertilization and exclosure experiment, we tested the effects of soil fertility and seedling predation by large herbivores on the survival rate of tree seedlings cooccurring with herbaceous vegetation in the field. Increased seedling predation by large herbivores might reduce tree recruitment in areas of high herbivore densities, such as found on nutrient hotspots (Grant and Scholes 2006). This might also explain the lower tree recruitment in fertile areas. The experiment was conducted in the APNR in an area open to wildlife. In this experiment, we transplanted pre-grown C. mopane seedlings (van der Waal et al. 2009) into field plots $(5 \times 10 \mathrm{~m})$ that were fertilized at increasing rates: 0 (control), $1.2 \mathrm{~g} \mathrm{~N} \mathrm{~m}^{-2}, 6 \mathrm{~g} \mathrm{~N} \mathrm{~m}^{-2}$, and $30 \mathrm{~g} \mathrm{~N} \mathrm{~m}^{-2}$. The grass layer was minimally disturbed during transplantation to avoid compromising the competition effect of grasses on tree seedlings. The fertilizer was spread by hand in December 2006, using a commercial NPK fertilizer (element ratio $=3 \mathrm{~N}: 2 \mathrm{P}: 1 \mathrm{~K}$ ). The experiment was replicated three times (total $n=12$ ). In December 2006, two groups, consisting of six C. mopane seedlings each, were transplanted into each plot (total $n=144)$. The one group was protected against large herbivore use with exclosures, while the second group was planted in the open. The exclosures ( $4 \mathrm{~m}$ in diameter) were constructed from standard fence poles, with 1.8-m-high wire netting and effectively excluded herbivores the size of hares and larger. Seedlings were transplanted after $54 \mathrm{~mm}$ of rain was received. No extra water was given during the experiment. Four months after transplantation, the seedlings were scored as 'alive' (green leaves or buds present) or 'dead' (green leaves and buds absent).

An additional pot experiment involved a competition experiment to test the hypothesis that the effect of herbaceous competition on tree seedlings intensifies with increasing soil fertility (Sankaran et al. 2008). For this purpose, we conducted a pot experiment with the topsoil collected in kraal and control sites, for which the inorganic $\mathrm{N}$ and extractable $\mathrm{P}$ concentrations were determined as described above. For each of the kraal and control sites $(2 \times 9)$, we filled three pots with the soil collected from kraal and control sites (see above). Per site, one pot was allocated a single grass seedling (either $U$. mosambicensis or $U$. panicoides, which could not be distinguished at the seedling stage), the second pot received a single $C$. mopane seedling, and the third pot, a mixture of a grass and a C. mopane seedling. Grass seedlings were grown in seedling trays before transplantation into pots. The $C$. mopane seedlings were obtained from a site where a large number of seedlings germinated, probably from the same nearby mother tree. $C$. mopane seedlings were allowed to establish in pots before grasses were planted into the mixture treatments. During the experiment, rainfall was supplemented with irrigation. After 3 months, seedling height, number of leaves, stem diameter and aboveground dry mass of $C$. mopane seedlings and above ground grass biomass (dried at $70^{\circ} \mathrm{C}$ to constant weight) were measured per pot. For the $C$. mopane seedlings, the relative competition index (RCI) was calculated for seedling height, leaf number, stem diameter and above ground biomass following Davis et al. (1998):

$\mathrm{RCI}=\frac{\text { Performance }_{\text {single }}-\text { Performance }_{\text {mixture }}}{X}$

where $X$ is the larger value of either single-plant performance (Performance single $_{\text {) }}$ ) or mixture-plant performance

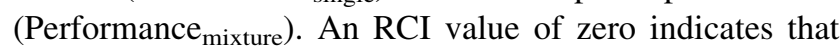
competitors had no effect on target plant performance and an RCI value of one indicates maximum competition intensity (competitive exclusion).

\section{Data analyses}

Paired $t$ tests were used for kraal-control comparisons of soil properties, the bioassay and herbaceous biomass. Because of the colinearity between soil texture classes, only differences between the sand fractions were tested. All percentage and concentration data were arcsine-transformed to improve the distribution of data. The herbaceous biomass and the bioassay data were logarithmically transformed, except the exclosure cage biomass data. The $\mathrm{pH}$ data were exponentially transformed. Wilcoxon signedrank tests were used to test for differences in woody density.

The difference between kraal and control sites for dung pile densities was tested with a generalized linear model. Since most species data were overdispersed, a negative binomial distribution was assumed. A logarithmic link 
function was used and transect size was entered as an offset-variable to account for the smaller transect sizes in some kraal sites.

A Kruskal-Wallis Chi-square test was used to test for impala dung pile number differences between bush-cleared and control sites.

A logistic regression analysis was used to test whether fertilizer (4 levels) and herbivore exclusion treatments (open vs protected) affected $C$. mopane seedling survival patterns in a full factorial model. In a control plot and a $1.2 \mathrm{~g} \mathrm{~N} \mathrm{~m}^{-2}$ fertilizer treatment plot, four and five seedlings, respectively, were dug out within weeks after transplantation, presumably by honey badgers Mellivora capensis. These data were omitted from the analysis. All statistical analyses were done in SPSS (v. 15).

\section{Results}

\section{Soil characteristics}

All sites had sandy top soils (Table 1). There was no difference in percentages sand $\left(t_{8}=-1.551, P>0.05\right)$ between controls and kraals (87 vs $92 \%$; Table 1 ).

The concentrations of inorganic $\mathrm{N}$, extractable $\mathrm{P}, \mathrm{Ca}, \mathrm{K}$ and $\mathrm{Mg}$ were on average higher in kraal top soils compared to control top soils, whereas $\mathrm{Na}$ and $\mathrm{Al}$ concentrations were not statistically different (Table 1). The mean $\mathrm{pH}$ of kraal soils was higher than the mean $\mathrm{pH}$ of control soils. Differences in the net nitrogen mineralization rate between kraal and control sites were not significant (Table 1). However, two sites received less than $38 \mathrm{~mm}$ rain during February ( $\approx$ incubation period), compared to $80-121 \mathrm{~mm}$ rain received at the remaining sites $(n=6)$. If the two dry sites are omitted, the net $\mathrm{N}$ mineralization rates in kraal sites were on average threefold higher than in control sites (Table 1). These results are consistent with those of the bioassay, as maize grown in kraal soils produced on average $9.5 \mathrm{~g}$ per pot, which is significantly more than the $3.9 \mathrm{~g}$ per pot of plants grown in control soils (Table 1).

Plant quality and quantity

$\mathrm{N}, \mathrm{P}$ and $\mathrm{K}$ concentrations in $U$. mosambicensis leaves were higher in kraal sites compared to control sites (Table 2). Differences in $\mathrm{Ca}, \mathrm{Mg}$ and $\mathrm{Na}$ concentrations were not significant.

The woody density of kraal sites was much lower than the density of control sites $(Z=-3.684, P<0.001)$. Only three woody plants were encountered in the nine kraal transects, which contrasts sharply with the median density of 1,700 plants $\mathrm{ha}^{-1}$ in controls (range, 200-3,000 plants $\mathrm{ha}^{-1}$ ). However, the aboveground herbaceous biomass on kraal sites was not significantly different from the control site biomass (Table 2).

\section{Herbivore use}

The mean herbaceous biomass inside exclosures after 8 weeks was $1,108 \mathrm{~kg} \mathrm{DM} \mathrm{ha}{ }^{-1}$, which is significantly

Table 1 A comparison of the textural and chemical properties of the topsoil ( $0-15 \mathrm{~cm}$ depth) of abandoned kraal sites with nearby controls sites in a semi arid savanna in South Africa

\begin{tabular}{|c|c|c|c|c|c|}
\hline \multirow[t]{2}{*}{ Characteristic } & \multirow[t]{2}{*}{$n$} & \multirow[t]{2}{*}{ Unit } & \multicolumn{2}{|l|}{ Mean $(95 \%$ CL) } & \multirow[t]{2}{*}{$P$} \\
\hline & & & Control & Kraal & \\
\hline \multicolumn{6}{|l|}{ Texture } \\
\hline Sand & 18 & $\%$ & $87(80-92)$ & $92(85-97)$ & ns \\
\hline \multicolumn{6}{|l|}{ Chemical } \\
\hline Inorganic N & 16 & $\mathrm{mg} \mathrm{kg}^{-1}$ & $2.6(0.7-5.7)$ & $8.1(2.5-16.9)$ & * \\
\hline $\mathrm{N}$ mineralization (all sites) & 16 & $\mathrm{mg} \mathrm{N} \mathrm{kg}{ }^{-1}$ day $^{-1}$ & $0.21(0.05-0.37)$ & $0.33(-0.08-0.73)$ & ns \\
\hline $\mathrm{N}$ mineralization (dry sites excluded) & 12 & $\mathrm{mg} \mathrm{N} \mathrm{kg}^{-1}$ day $^{-1}$ & $0.18(-0.02-0.38)$ & $0.55(0.26-0.84)$ & $*$ \\
\hline $\mathrm{P}$ & 18 & $\mathrm{mg} \mathrm{kg}^{-1}$ & $5.6(2.2-10.5)$ & $144.9(79.2-230.2)$ & $* *$ \\
\hline $\mathrm{Ca}$ & 18 & $\mathrm{mg} \mathrm{kg}^{-1}$ & $847(616-1,115)$ & $2,794(1,935-3,810)$ & $* *$ \\
\hline $\mathrm{Mg}$ & 18 & $\mathrm{mg} \mathrm{kg}^{-1}$ & $226(143-328)$ & $498(365-651)$ & $*$ \\
\hline $\mathrm{K}$ & 18 & $\mathrm{mg} \mathrm{kg}^{-1}$ & $290(217-374)$ & $643(462-854)$ & ** \\
\hline $\mathrm{Na}$ & 18 & $\mathrm{mg} \mathrm{kg}^{-1}$ & $11(7-15)$ & $16(10-26)$ & ns \\
\hline Al & 18 & $\mathrm{mg} \mathrm{kg}^{-1}$ & $7.5(7.1-8.0)$ & $7.9(6.4-9.5)$ & ns \\
\hline $\mathrm{pH}$ (water) & 18 & $\mathrm{mg} \mathrm{kg}^{-1}$ & $6.3(6.2-6.4)$ & $7.6(7.3-7.9)$ & $* * *$ \\
\hline Bio-assay (Zea mays) & 16 & $\mathrm{~g} \operatorname{pot}^{-1}$ & $3.9(2.7-5.8)$ & $9.5(6.7-13.5)$ & $*$ \\
\hline
\end{tabular}

Inorganic $\mathrm{N}$ refers to the total extractable nitrate and ammonium measured at time zero. The results of a bioassay with standard maize are also indicated. Back transformed means and $95 \%$ confidence limits are given

Significance levels $* * * P<0.001, * * P<0.01, * P<0.05$, ns $P \geq 0.05$ 
Table 2 A comparison between control and kraal sites in terms of the leaf chemistry of Urochloa mosambicensis leaves sampled in control and kraal sites, the herbaceous above ground biomass (dry mass), herbaceous biomass (dry mass) off take by large herbivores and the percentage of herbaceous plants grazed

\begin{tabular}{|c|c|c|c|c|c|}
\hline \multirow[t]{2}{*}{ Characteristic } & \multirow[t]{2}{*}{$n$} & \multirow[t]{2}{*}{ Unit } & \multicolumn{2}{|l|}{ Mean $(95 \% \mathrm{CL})$} & \multirow[t]{2}{*}{$P$} \\
\hline & & & Control & Kraal & \\
\hline \multicolumn{6}{|l|}{ Leaf } \\
\hline $\mathrm{N}$ & 17 & $\%$ & $1.6(0.8-2.6)$ & $2.8(2.2-3.3)$ & $* *$ \\
\hline \multicolumn{6}{|l|}{ Chemistry } \\
\hline $\mathrm{P}$ & 17 & $\%$ & $0.13(0.06-0.23)$ & $0.46(0.33-0.61)$ & $* *$ \\
\hline $\mathrm{K}$ & 17 & $\%$ & $2.15(1.1-3.6)$ & $3.58(2.96-4.27)$ & $* *$ \\
\hline $\mathrm{Ca}$ & 17 & $\%$ & $0.57(0.28-0.95)$ & $0.73(0.67-0.79)$ & $\mathrm{ns}$ \\
\hline $\mathrm{Mg}$ & 17 & $\%$ & $0.26(0.13-0.44)$ & $0.39(0.29-0.49)$ & $\mathrm{ns}$ \\
\hline $\mathrm{Na}$ & 17 & $\%$ & $0.24(0.11-0.42)$ & $0.20(0.12-0.31)$ & $\mathrm{ns}$ \\
\hline \multicolumn{6}{|l|}{ Biomass } \\
\hline Herbaceous above ground & 18 & $\mathrm{~kg} \mathrm{DM} \mathrm{ha}{ }^{-1}$ & $928(562-1,532)$ & $781(494-1,233)$ & ns \\
\hline \multicolumn{6}{|l|}{ Utilization } \\
\hline Herbaceous off-take & 16 & $\mathrm{~kg} \mathrm{DM} \mathrm{ha}{ }^{-1}$ day $^{-1}$ & $6(0-5)$ & $9(5-13)$ & ns \\
\hline Herbaceous plants & 18 & $\%$ & $12(6-21)$ & $45(29-62)$ & $* *$ \\
\hline
\end{tabular}

The sampling and measurements were done in February 2007. Back transformed means, 95\% confidence limits and the significance level of group differences are given

Significance levels $* * * P<0.001, * * P<0.01, * P<0.05$, ns $P \geq 0.05$

higher than the $621 \mathrm{~kg} \mathrm{DM} \mathrm{ha}^{-1}$ measured outside cages at kraal sites $\left(t_{7}=4.31, P<0.01\right)$. At control sites, the difference between the herbaceous biomass inside and outside of exclosures was not significant $(P>0.05)$, indicating that grazers significantly reduced swards at kraal sites but not at control sites. In agreement, the frequency of herbaceous plant utilization was more than threefold higher on kraal sites than on control sites (Table 2).

Dung accumulation and herbivore species composition

The density of all large herbivore dung piles combined was higher in kraal sites than control sites (Wald Chisquare $=22.9, P<0.001)$. Individual species with significantly higher average dung accumulation rates on kraal sites were impala, duiker, waterbuck and steenbok. The densities of buffalo, elephant, giraffe and warthog were not higher on kraals compared to controls (Table 3). No dung of kudu or wildebeest were found in control transects (Table 3).

Using mean dung pile dry mass and the mean fecal $\mathrm{N}$ and $\mathrm{P}$ content values, the $\mathrm{N}$ inputs by individual species were calculated (Table 3). The $\mathrm{N}$ deposition rate through large herbivore dung at kraal sites was calculated as $1.2 \mathrm{~g} \mathrm{~N} \mathrm{~m}^{2}$ year ${ }^{-1}$, compared to only $0.1 \mathrm{~g} \mathrm{~N} \mathrm{~m}^{2}$ year $^{-1}$ for control sites. At kraal sites, impala deposited the most $\mathrm{N}$ (on average $40 \%$ of total), followed by elephant $(31 \%)$ and giraffe (8\%). Conversely, at control sites, elephants deposited the most $\mathrm{N}$ (on average 53\% of total), followed by giraffe (18\% of total) and impala (16\% of total; Table 3). In the experiment where vegetation structure was altered, open areas themselves attracted more herbivores such as impala. Shortly after clearing, four times more (Chi-square $=4.2, d f=1, P<0.05$ ) impala dung piles were recorded in bush-cleared sites compared to control sites covering the same surface area (564 vs. 138 dung piles).

Soil nutrients, herbivore use and tree recruitment

For the field fertilization and exclosure experiment, transplanted $C$. mopane survival after 4 months in the field was significantly related to fertilizer treatments (Wald Chisquare $=13.981, d f=3, P<0.01$; Fig. 1$)$, but was neither related to herbivore exclusion (Wald Chi-square $=0.448$, $d f=1, P>0.05)$ or the fertilizer $\times$ exclosure interaction (Wald Chi-square $=5.104, d f=3, P>0.05$ ). For the fertilizer treatments, the establishment success was significantly lower in the 6 and $30 \mathrm{~g} \mathrm{~N} \mathrm{~m}^{-2}$ treatments compared to controls, but not for the $1.2 \mathrm{~g} \mathrm{~N} \mathrm{~m}^{-2}$ treatment (Fig. 1).

The pot experiment data suggest that herbaceous competition intensified with increasing soil $\mathrm{N}$ and $\mathrm{P}$ availability. The relative competition index, RCI, for leaf number per tree seedling was positively correlated with inorganic soil $\mathrm{N}$ and $\mathrm{P}$ concentration, indicating that seedlings grew less under fertile conditions when 
Table 3 A comparison between control $(n=9)$ and kraal sites $(n=9)$ of the dung pile deposition rates $\left(\right.$ dung piles ha ${ }^{-1}$ day $\left.^{-1}\right)$ of large herbivore species

\begin{tabular}{|c|c|c|c|c|c|c|c|c|}
\hline \multirow[t]{2}{*}{ Species } & \multirow[t]{2}{*}{ Numbers } & \multicolumn{2}{|c|}{$\begin{array}{l}\text { Dung pile deposition rate } \\
\left(\text { piles } \mathrm{ha}^{-1} \text { day }^{-1} \text { ) }\right.\end{array}$} & \multirow[t]{2}{*}{$P$} & \multirow[t]{2}{*}{$\begin{array}{l}\text { Mean dung pile } \\
\text { mass }(g)\end{array}$} & \multirow[t]{2}{*}{$\% \mathrm{~N}$ in dung } & \multicolumn{2}{|c|}{$\begin{array}{l}\text { Dung } \mathrm{N} \text { deposition rate } \\
\left(\mathrm{g} \mathrm{N} \mathrm{ha}^{-1} \text { day }^{-1}\right)\end{array}$} \\
\hline & & Control & Kraal & & & & Control & Kraal \\
\hline Impala & 7,649 & $1.2 \pm 1.5$ & $24.7 \pm 20.1$ & $* * *$ & 28.8 & 1.73 & 0.61 & 12.36 \\
\hline Steenbok & - & $0.1 \pm 0.1$ & $0.9 \pm 1.2$ & $*$ & 6.6 & 2.27 & 0.01 & 0.14 \\
\hline Duiker & - & $0.2 \pm 0.1$ & $4.4 \pm 3.2$ & $* * *$ & 9.6 & 2.30 & 0.04 & 0.97 \\
\hline Kudu & 385 & 0.0 & $0.1 \pm 0.2$ & - & 172.9 & 1.84 & 0.00 & 0.35 \\
\hline Giraffe & 320 & $0.1 \pm 0.1$ & $0.4 \pm 0.6$ & $\mathrm{~ns}$ & 289.5 & 2.08 & 0.68 & 2.66 \\
\hline Warthog & 163 & $<0.1 \pm 0.1$ & $<0.1 \pm 0.1$ & ns & 116.3 & 1.66 & 0.05 & 0.09 \\
\hline Elephant & 569 & $0.5 \pm 0.3$ & $2.2 \pm 1.9$ & ns & 384.0 & 1.17 & 2.01 & 9.81 \\
\hline Buffalo & 1,657 & $0.1 \pm 0.1$ & $0.3 \pm 0.5$ & ns & 221.2 & 1.15 & 0.21 & 0.67 \\
\hline Wildebeest & 102 & 0.0 & $<0.1 \pm 0.1$ & - & 186.0 & 1.24 & 0.00 & 0.10 \\
\hline Waterbuck & 95 & $0.1 \pm 0.1$ & $1.9 \pm 2.2$ & $* * *$ & 199.8 & 1.16 & 0.18 & 4.39 \\
\hline Total & & & & & & & 3.97 & 31.54 \\
\hline
\end{tabular}

In addition, the nitrogen deposited in dung is calculated for control and kraal sites from mean dung pile weights and mean dung $\mathrm{N}$ concentration per species. Animal census numbers for a total helicopter count in 2006 of the area where six kraal-control site pairs were located are also given. No dung was recorded in control sites for kudu and wildebeest. Means $\pm \mathrm{SE}$ are given

Significance levels *** $P<0.001$, ** $P<0.01, * P<0.05$, ns $P \geq 0.05$

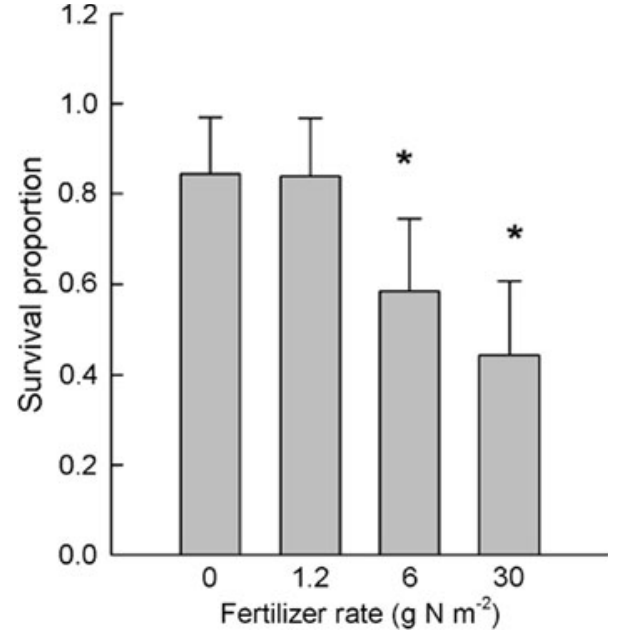

Fig. 1 The effect of fertilization on Colophospermum mopane tree seedling survival. The proportion of tree seedlings that survived 4 months after transplantation into the field in areas fertilized at 0 , $1.2,6.0$ and $30.0 \mathrm{~g} \mathrm{~N} \mathrm{~m}^{-2}$. Significant differences $(P<0.05)$ from control survival are indicated with asterisks above fertilizer rate treatments. The seedlings $(n=144)$ were planted after a $58-\mathrm{mm}$ rain event in December 2006, taking care that the grass layer was minimally disturbed. Mortalities occurred during a mid-season drought in January 2007, when only $28 \mathrm{~mm}$ was recorded. Error bars indicate $95 \%$ confidence limits

competing with grasses (Fig. 2). Likewise, stem diameter RCI increased with increasing inorganic N. The RCI values for seedling height and aboveground biomass showed positive trends (Fig. 2), but these were not statistically significant $(P>0.05)$.

\section{Discussion}

We assumed that the soil nutrient differences between kraal and control sites were initiated by livestock management and not by other determinants of soil fertility, i.e., geological parent material (e.g., granite vs gabbro in the study area; Venter et al. 2003) and other biotic agents such as termites (Grant and Scholes 2006) or large trees (Ludwig et al. 2004). The boundaries of kraal sites were still clearly visible in terms of plant species composition, structure and herbivore activity, which were confirmed to align with former kraal perimeter structures. This suggests that herbivores were the primary cause of the observed soil fertility differences: initially by penning livestock at night and evidently thereafter by free-ranging wild herbivores.

Our data provide evidence that large herbivores may influence the structure of savanna vegetation indirectly via control over soil nutrient availability. We propose that the observed patterns reflect soil-plant-herbivore feedbacks (Fig. 3). Management of livestock in the study area left behind a legacy of nutrient hotpots after livestock were removed. On average, the availability of elements such as $\mathrm{P}$ was 25 -fold higher in kraal than in control soils about 40 years after abandonment. This is similar to the 19 -fold increase in extractable $\mathrm{P}$ found in boma compared to bushland sites in Laikipia, Kenya (Augustine et al. 2003). Our hypothesis is that this resulted in locally enhanced sward productivity and quality, which attracted wild herbivores. In turn, we suggest that wild herbivores may have maintained, or possibly even increased, local nutrient 

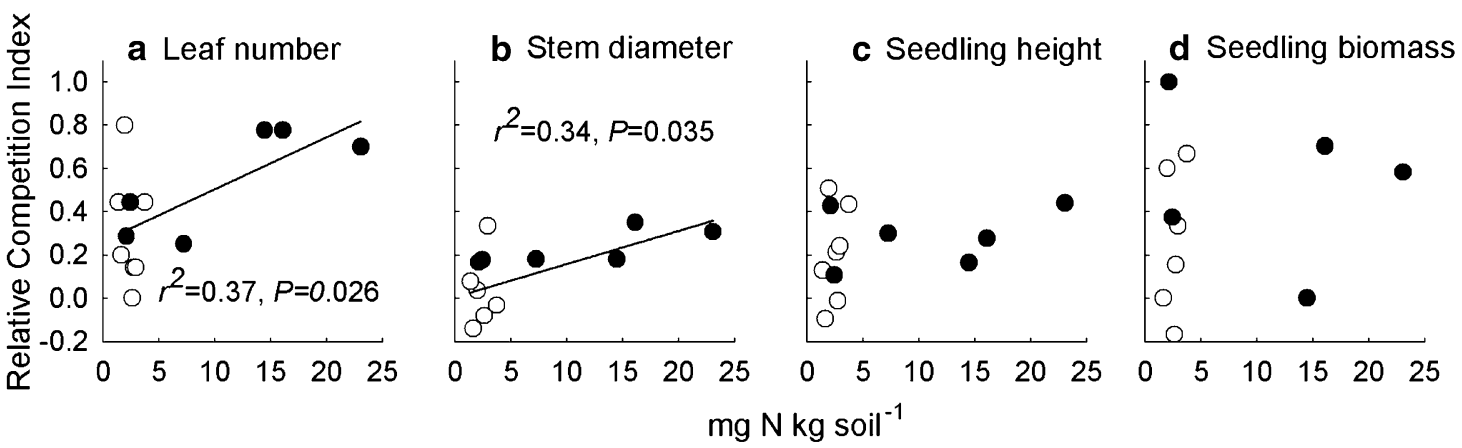

$\mathrm{mg} \mathrm{N} \mathrm{kg} \mathrm{soil}^{-1}$
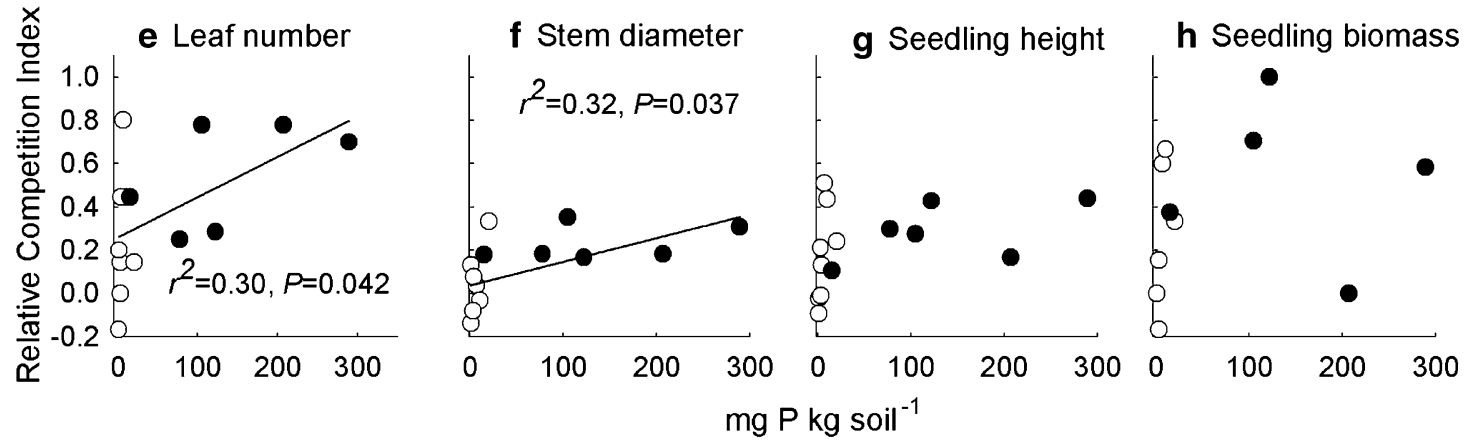

Fig. 2 Relative Competition Index (RCI) values of Colophospermum mopane seedling leaf number, stem diameter, seedling height and biomass (above ground) in relation to inorganic soil $\mathrm{N}$ concentration (a-d) and extractable soil P concentration $(\mathbf{e}-\mathbf{h})$. RCI values greater than 0 indicate that single $C$. mopane seedlings were relatively suppressed if grown with a single grass plant, while values below 0 suggest facilitation of seedlings by grasses. The soils used in the experiment were collected from abandoned kraal (closed symbols) and control sites (open symbols) in the study area

therefore has a long residence time in soils (Blackmore et al. 1990; Augustine 2003). In the absence of herbivores after about four decades, we would expect lower $\mathrm{N}$ values than we have measured in the kraal soils, which were well used by wild herbivores.

It seems likely that wild herbivores increased kraal nutrient availability by (1) accelerating nutrient cycling and (2) by importing nutrients from the surrounding landscape (Fig. 3; Blackmore et al. 1990; Augustine 2003, 2004). First, the kraal data fit the accelerated nutrient cycling scenario proposed by Ritchie et al. (1998), which appears to be characteristic of fertile systems (Bardgett and Wardle 2003). We found that herbivores grazed grass plants intensively, while depositing large amounts of nutrients through dung (and presumably urine) at kraal sites (Table 2). Through these actions, large herbivores provide a shortcut to the slow nutrient release from plant litter through decomposition, by rapidly processing vegetation and recycling nutrients through dung and urine (Bardgett and Wardle 2003). In addition, the higher $\mathrm{N}$ mineralization rates of kraal sites (provided that enough rain falls) might be due to the stimulation of decomposer activity by animal excreta and the high quality of leaf litter in kraals (Bardgett and Wardle 2003). The average $\mathrm{N}$ mineralization rate (excluding dry sites) for kraals $\left(0.55 \mathrm{~g} \mathrm{~N} \mathrm{~kg} \mathrm{soil}^{-1}\right.$ day $\left.^{-1}\right)$ 


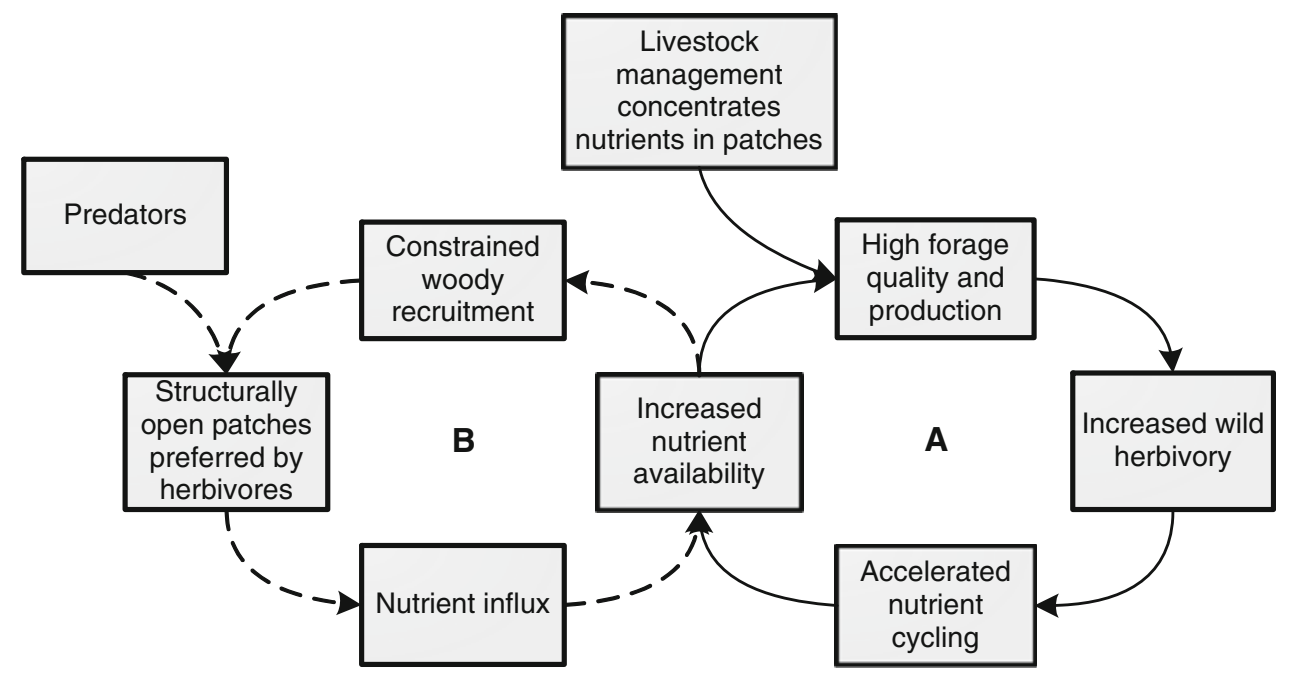

Fig. 3 A hypothetical model explaining how kraals may have persisted as structurally open nutrient hotspots after livestock were replaced by wild herbivores in the study area. We propose that two reinforcing feed back loops developed. The first (feedback loop A, solid-line arrows) developed when livestock penning locally increased nutrient availability through dung and urine deposits. After livestock were removed, forage productivity and quality increased here, which attracted wild herbivores. In turn the increased herbivore activities accelerate nutrient cycling, hence nutrient availability in a positive feedback loop. In the second feed back loop (feedback loop $B$, dashed-line arrows), anti-predator behaviour of wild herbivore species caused an influx of nutrients into kraals, which increased the availability of soil nutrients. This constrained woody recruitment, which kept kraals structurally open. Because of bush encroachment in the surrounding areas, the open kraal sites were increasingly perceived as predator-safe areas, which uphold the influx of nutrient into kraal sites

U. mosambicensis leaf $\mathrm{N}$ concentration 1.75 times higher in kraals than controls), our data suggest that $\mathrm{N}$ consumption and export from kraals were less than three times that of controls. Assuming that the overall nutrient pool in the study system remains constant over time, our data strongly suggest that wild herbivores caused an $\mathrm{N}$ (and other nutrients) influx into kraal sites. The surrounding areas, represented by the control sites, subsidized these nutrients (De Mazancourt et al. 1998; Augustine 2003). At a landscape scale, the redistribution of nutrients by both domesticated and wild herbivores was probably insignificant given the small area covered by kraal sites in the study area. Nevertheless, the role of large herbivores in creating and maintaining soil nutrient heterogeneity is presently underappreciated in semi-arid savannas (Jacobs et al. 2007).

It is important to note that herbivore responses to higher forage quality alone is unlikely to create strong nutrient redistribution effects, because the high nutrient intake will be largely offset by nutrient excretion while grazing. Spending non-foraging time in an area is required for significant nutrient redistribution to occur. The bushclearing experiment in the study area indicates that a nutrient influx by impala, the most numerous species in the study area, occurred when patches were cleared of its woody component. This implies that impala were attracted by the openness of the habitat, a preference also noted by Estes (1992). This, in turn, might explain the disproportionately high impala dung deposition rates at kraal sites, 
suggesting an influx of nutrients into these open sites. In Laikipia, Kenya, impala also preferred to spend time in structurally open boma sites, even during the dry season when forage resources were depleted (Augustine 2004). As a result, impala imported nutrients from the surrounding bushland areas into the boma sites, resulting in the persistence of these nutrient hotspots over time (Augustine 2003, 2004).

There is ample evidence from savanna studies that large herbivores prefer open areas when under predation threat. Valeix et al. (2009) recently concluded that herbivores prefer open areas when lions were in the vicinity in Hwange National Park, Zimbabwe. Riginos and Grace (2008) found that savanna herbivores (except species immune to wild predators, e.g., elephants) prefer open areas with unobstructed visibility, apparently to improve predator detection. The point is that, in dense woodland areas, patches offering good visibility such as the abandoned kraal sites in the study area stand out as safe havens for herbivores dependent on vigilance to avoid predation. Given the low density of kraal sites in the study area, it is unlikely that the presence of kraal sites significantly altered predator-prey dynamics in the general study area.

\section{Tree recruitment constraints}

Our data clearly showed that woody recruitment was more constrained under fertile conditions than infertile ones, when competing with herbaceous plants. Woody plants failed to re-colonize fertile kraal sites since their abandonment, while bush encroachment prevails in the general study area (G. Roux, unpublished data). This trend (bush encroachment) was also observed in the KNP's granitic areas (Eckhardt et al. 2000).

The results of our experiments show that the effect of herbaceous competition on tree seedlings intensified under fertile conditions and that this may lead to increased mortality rates of tree seedlings establishing under fertile conditions. This was also found in other experiments with tree seedlings and grasses (Cohn et al. 1989; van der Waal et al. 2009) and suggests that the openness of kraal sites might at least partially be explained by the suppressing effects of herbaceous competition on tree recruitment (Sankaran et al. 2008). In contrast, Reid and Ellis (1995) found that abandoned cattle bomas facilitated rather than suppressed shrub (Acacia tortilis) recruitment in Turkana, Kenya. Their results may be attributed to the much lower rainfall of about $300 \mathrm{~mm}$, where perennial grasses are mostly absent, and grass competition consequently weaker, or may indicate that certain tree species are exceptions in this regard. A. tortilis is for instance often the only species colonizing nutrient hotspot areas (Belsky and Amundson 1986; Blackmore et al. 1990). In our study area, A. tortilis was scarce, and in the study area of Augustine et al. (2003), Laikipia, Kenya, it did not occur. A contributing factor limiting tree recruitment may have been tree germination constraints imposed by soil characteristics, which were not considered in this study. Roem et al. (2002), for example, found that the germination of several heathland species was affected by nutrient availability, although this effect was subsidiary to soil acidity. It is unlikely that seed dispersal limited tree recruitment, as mature trees occurred in close proximity to kraal sites.

An alternative explanation for the low tree recruitment rates in fertile patches (e.g., kraals) may also be that fertile areas attract more herbivores, which translate into higher woody seedling browsing and trampling rates (Augustine and McNaughton 2004). For example, the dung accumulation data suggest that impala occupied kraal sites on average 20 times more often than the control sites. Since impala are known seedling predators (Prins and van der Jeugd 1993; Sharam et al. 2006), this could translate into higher seedling predation rates in fertile areas. However, the data of the field fertilization and exclosure experiment, conducted in an area where impala were common, did not support this contention, although we acknowledge that the short study period prevent firm conclusions in this regard. Our results are consistent with those of Augustine and coworkers who concluded, after a 2-year herbivore exclusion experiment, that tree seedling predation by large herbivores, including impala, was not higher on fertile bomas, in spite of significantly higher animal densities on these sites (Augustine et al. 2003; Augustine and McNaughton 2004). In a forest system in Poland, Kuijper et al. (2010) also did not find an interaction between soil fertility and predation by ungulates on tree seedlings. In fact, Goheen et al. (2004) found that large herbivores facilitated tree seedling survival in a Kenyan savanna by suppressing rodent and invertebrate predation of seedlings, and Fornara and du Toit (2008) found higher Acacia sapling densities in a highherbivory area compared to a low-herbivory area in the KNP. Herbivores occurring at high densities can, however, have strong direct effects on tree cover by suppressing the recruitment of saplings into larger size classes (e.g., savanna, Augustine and McNaughton 2004; Fornara and Du Toit 2008; temperate forest, Kuijper et al. 2010).

\section{Conclusions}

Our results show that, by influencing local soil nutrient availability, first livestock and probably wild herbivores after the livestock were removed, indirectly exerted longlasting effects on the habitat quality and vegetation structure of kraal sites through their effect on soil nutrient availability. Although kraals cover only a small fraction, the maintenance of abandoned kraals by wild herbivores 
contributes to the structural heterogeneity of the study area. In nutrient-poor savannas, fertile patches, e.g., beneath large trees, termite mounds, sodic patches and abandoned livestock management areas, provide important sources of scarce nutrients to herbivores (Augustine et al. 2003; Grant and Scholes 2006; Mourik et al. 2007; Treydte et al. 2007; Ludwig et al. 2008; Treydte et al. 2008). In addition, if the anti-predator behavior of large herbivores indeed causes the maintenance of abandoned kraal sites as structurally open, nutrient hotspot areas (Fig. 3), then this is an example of a top-down cascading effect in which predators affect consumers, which in turn feed back to primary producers via control over a limiting soil resource. Such an ecological cascade may not be limited to abandoned kraal sites in nutrient-poor savannas but may also operate in other systems, upholding resource heterogeneity.

Acknowledgments We thank the management of the APNR for allowing us to work in the reserves and the Dr. Marie Luttig Trust for providing accommodation. We particularly thank Colin Rowles, Mrs. S. Blatherwick, Carl van den Berg, and Marius Fuls for logistical assistance during the project. Moagi Keretetse, Wim Braakhekke, Jan Bokdam and Claudius van de Vijver are thanked for useful scientific input. Many thanks to Reis Manhique, Floris van Beest and Lemson Monareng for help in the field. We also thank Shell-SA for a fuel donation and Omnia for donating fertilizer. The research was funded by NWO-WOTRO (grant no. W01.65.216, C.v.d.W.) and the DELTA fund (A.K.). A.K. is also indebt to Peter Kool and Carin van Drunen for financial support. Financial support to S.M. was provided by a grant from the Stichting Dr. Hendrik Muller's Vaderlandsch Fonds.

Open Access This article is distributed under the terms of the Creative Commons Attribution Noncommercial License which permits any noncommercial use, distribution, and reproduction in any medium, provided the original author(s) and source are credited.

\section{References}

Anderson et al (2010) Ecology's cruel dilemma, phylogenetic trait evolution and the assembly of Serengeti plant communities. $\mathrm{J}$ Ecol (in press)

Anonymous (1990) Handbook of standard soil testing methods for advisory purposes. Soil Science Society of South Africa, Pretoria

Augustine DJ (2003) Long-term, livestock-mediated redistribution of nitrogen and phosphorus in an East African savanna. J Appl Ecol 40:137-149

Augustine DJ (2004) Influence of cattle management on habitat selection by impala on central Kenyan rangeland. J Wildl Manage 68:916-923

Augustine DJ, McNaughton SJ (2004) Regulation of shrub dynamics by native browsing ungulates on East African rangeland. J Appl Ecol 41:45-58

Augustine DJ, McNaughton SJ (2006) Interactive effects of ungulate herbivores, soil fertility, and variable rainfall on ecosystem processes in a semi-arid savanna. Ecosystems 9:1242-1256

Augustine DJ, McNaughton SJ, Frank DA (2003) Feedbacks between soil nutrients and large herbivores in a managed savanna ecosystem. Ecol Appl 13:1325-1337
Bardgett RD, Wardle DA (2003) Herbivore-mediated linkages between aboveground and belowground communities. Ecology 84:2258-2268

Belsky AJ, Amundson RG (1986) Sixty years of successional history behind a moving sand dune near Olduvai Gorge, Tanzania. Biotropica 18:231-235

Bigalke RC (2000) Functional relationships between protected and agricultural areas in South Africa and Namibia. In: Prins HHT, Groothuis JG, Dolan TT (eds) Wildlife conservation by sustainable use. Kluwer, Boston, pp 169-202

Blackmore AC, Mentis MT, Scholes RJ (1990) The origin and extent of nutrient-enriched patches within a nutrient-poor savanna in South-Africa. J Biogeogr 17:463-470

Bokdam J (2001) Effects of browsing and grazing on cyclic succession in nutrient-limited ecosystems. J Veg Sci 12:875-886

Bransby DI, Tainton NM (1977) The disc pasture meter: possible applications in grazing management. Afr $\mathrm{J}$ Range For Sci $12: 115-118$

Coates Palgrave K, Coates Palgrave M, Drummond RB, Moll EJ (2002) Trees of Southern Africa. Struik, Cape Town

Coetsee C, February EC, Bond WJ (2008) Nitrogen availability is not affected by frequent fire in a South African savanna. J Trop Ecol 24:647-654

Cohn EJ, van Auken OW, Bush JK (1989) Competitive interactions between Cynodon dactylon and Acacia smallii seedlings at different nutrient levels. Am Midl Nat 121:265-272

Davis MA, Wrage KJ, Reich PB (1998) Competition between tree seedlings and herbaceous vegetation: support for a theory of resource supply and demand. J Ecol 86:652-661

De Mazancourt C, Loreau M, Abbadie L (1998) Grazing optimization and nutrient cycling: when do herbivores enhance plant production? Ecology 79:2242-2252

Eckhardt H, van Wilgen BW, Biggs HC (2000) Trends in woody vegetation cover in the Kruger National Park, South Africa, between 1940 and 1998. Afr J Ecol 38:108-115

Estes RD (1992) The behavior guide to African mammals. University of California Press, Los Angeles

Fornara DA, Du Toit JT (2008) Responses of woody saplings mammalian herbivory in an exposed to chronic African savanna. Ecoscience 15:129-135

Gibbs Russell GE, Watson L, Koekemoer M, Smook L, Barker NP, Anderson HM, Dallwitz MJ (1990) Grasses of southern Africa. Mem Bot Surv S Afr 58:1-437

Gillson L, Ekblom A (2009) Resilience and thresholds in savannas: nitrogen and fire as drivers and responders of vegetation transition. Ecosystems 12:1189-1203

Goheen JR, Keesing F, Allan BF, Ogada DL, Ostfeld RS (2004) Net effects of large mammals on Acacia seedling survival in an African savanna. Ecology 85:1555-1561

Grant CC, Scholes MC (2006) The importance of nutrient hotspots in the conservation and management of large wild mammalian herbivores in semi-arid savannas. Biol Conserv 130:426-437

Hanan NP, Sea WB, Dangelmayr G, Govender N (2008) Do fires in savannas consume woody biomass? A comment on approaches to modeling savanna dynamics. Am Nat 171:851-856

Heisler JL, Briggs JM, Knapp AK, Blair JM, Seery A (2004) Direct and indirect effects of fire on shrub density and aboveground productivity in a mesic grassland. Ecology 85:2245-2257

Hejcman M, Klaudisova M, Stursa J, Pavlu V, Schellberg J, Hejcmanova P, Hakl J, Rauch O, Vacek S (2007) Revisiting a 37 years abandoned fertilizer experiment on Nardus grassland in the Czech Republic. Agric Ecosyst Environ 118:231-236

Holdo RM, Holt RD, Coughenour MB, Ritchie ME (2007) Plant productivity and soil nitrogen as a function of grazing, migration and fire in an African savanna. J Ecol 95:115-128 
Jacobs SM, Bechtold JS, Biggs HC, Grimm NG, Lorentz S, McClain ME, Naiman RJ, Perakis SS, Pinay G, Scholes MC (2007) Nutrient vectors and riparian processing: a review with special reference to African semiarid savanna ecosystems. Ecosystems 10:1231-1249

Jewell PL, Kauferle D, Gusewell S, Berry NR, Kreuzer M, Edwards PJ (2007) Redistribution of phosphorus by mountain pasture in cattle on a traditional the Alps. Agric Ecosyst Environ 122:377386

Juchnowicz-Bierbasz M, Rakusa-Suszczewski S (2002) Nutrients and cations content in soil solutions from the present and abandoned penguin rookeries (Antarctica, King George Island). Pol J Ecol 50:79-91

Kingdon J (1997) The Kingdon Field Guide to African Mammals. Academic, London

Kraaij T, Ward D (2006) Effects of rain, nitrogen, fire and grazing on tree recruitment and early survival in bush-encroached savanna, South Africa. Plant Ecol 186:235-246

Kuijper DPJ, Cromsigt JPGM, Jedrzejewska B, Miscicki S, Churski M, Jedrzejewski W, Kweczlich I (2010) Bottom-up versus topdown control of tree regeneration in the Białowieza Primeval Forest, Poland. J Ecol 98:888-899

Ludwig F, de Kroon H, Berendse F, Prins HHT (2004) The influence of savanna trees on nutrient, water and light availability and the understorey vegetation. Plant Ecol 170:93-105

Ludwig F, de Kroon H, Prins HHT (2008) Impacts of savanna trees on forage quality for a large African herbivore. Oecologia 155:487496

MacGregor MD, O'Connor TG (2002) Patch dieback of Colophospermum mopane in a dysfunctional semi-arid African savanna. Austral Ecol 27:385-395

McNaughton SJ, Milchunas DG, Frank DA (1996) How can net primary productivity be measured in grazing ecosystems? Ecology 77:974-977

McNaughton SJ, Banyikwa FF, McNaughton MM (1997) Promotion of the cycling of diet-enhancing nutrients by African grazers. Science 278:1798-1800

Moe SR, Wegge P (2008) Effects of deposition of deer dung on nutrient redistribution and on soil and plant nutrients on intensively grazed grasslands in lowland Nepal. Ecol Res 23:227-234

Mourik AA, van Langevelde F, van Tellingen E, Heitkönig IMA, Gaigher I (2007) Stability of wooded patches in a South African nutrient-poor grassland: do nutrients, fire or herbivores limit their expansion? J Trop Ecol 23:529-537

Novozamsky I, Houba VJG, Vaneck R, Vanvark W (1983) A novel digestion technique for multi-element plant analysis. Commun Soil Sci Plant 14:239-248

Prins HHT, van der Jeugd HP (1993) Herbivore population crashes and woodland structure in East Africa. J Ecol 81:305-314

Reid RS, Ellis JE (1995) Impacts of pastoralists on woodland in South Turkana, Kenya: livestock mediated tree recruitment. Ecol Appl 5:978-992

Riginos C, Grace JB (2008) Savanna tree density, herbivores, and the herbaceous community: bottom-up vs. top-down effects. Ecology 89:2228-2238

Ritchie ME, Tilman D, Knops JMH (1998) Herbivore effects on plant and nitrogen dynamics in oak savanna. Ecology 79:165-177

Robertson GP, Coleman DC, Bledsoe CS, Sollins P (1999) Standard soil methods for long-term ecological research. Oxford University Press, New York

Roem WJ, Klees H, Berendse F (2002) Effects of nutrient addition and acidification species diversity and seed germination. $\mathbf{J}$ Appl Ecol 39:937-948

Sammis T (1996) Soil texture analysis. http://weather.nmsu_edu/ teaching_Material/soil456/soiltexture/soiltext.htm
Sankaran M, Ratnam J, Hanan NP (2004) Tree-grass coexistence in savannas revisited - insights from an examination of assumptions and mechanisms invoked in existing models. Ecol Lett 7:480-490

Sankaran M, Hanan NP, Scholes RJ, Ratnam J, Augustine DJ, Cade BS, Gignoux J, Higgins SI, Le Roux X, Ludwig F, Ardo J, Banyikwa F, Bronn A, Bucini G, Caylor KK, Coughenour MB, Diouf A, Ekaya W, Feral CJ, February EC, Frost PGH, Hiernaux P, Hrabar H, Metzger KL, Prins HHT, Ringrose S, Sea W, Tews J, Worden J, Zambatis N (2005) Determinants of woody cover in African savannas. Nature 438:846-849

Sankaran M, Ratnam J, Hanan N (2008) Woody cover in African savannas: the role of resources, fire and herbivory. Glob Ecol Biogeogr 17:236-245

Schlesinger WH, Raikes JA, Hartley AE, Cross AF (1996) On the spatial pattern of soil nutrients in desert ecosystems. Ecology 77:364-374

Scholes RJ, Archer SR (1997) Tree-grass interactions in savannas. Annu Rev Ecol Syst 28:517-544

Sharam G, Sinclair ARE, Turkington R (2006) Establishment of broad-leaved thickets in Serengeti, Tanzania: the influence of fire, browsers, grass competition, and elephants. Biotropica 38:599-605

Singer FJ, Schoenecker KA (2003) Do ungulates accelerate or decelerate nitrogen cycling? For Ecol Manag 181:189-204

Smit GN (2001) The influence of tree thinning on the vegetative growth and browse production of Colophospermum mopane. S Afr J Wildl Res 31:99-114

Treydte AC, Heitkönig IMA, Prins HHT, Ludwig F (2007) Trees improve grass quality for herbivores in African savannas. Perspect Plant Ecol 8:197-205

Treydte AC, van Beeck FAL, Ludwig F, Heitkönig IMA (2008) Improved quality of beneath-canopy grass in South African savannas: local and seasonal variation. J Veg Sci 19:663-670

Valeix M, Loveridge AJ, Chamaille-Jammes S, Davidson Z, Murindagomo F, Fritz F, Macdonald DW (2009) Behavioral adjustments of African herbivores to predation risk by lions: spatiotemporal variations influence habitat use. Ecology 90:23-30

van der Waal C, de Kroon H, de Boer WF, Heitkönig IMA, Skidmore AK, de Knegt HJ, van Langevelde F, van Wieren SE, Grant CC, Page BR, Slotow R, Kohi EM, Mwakiwa E, Prins HHT (2009) Water and nutrients alter herbaceous competitive effects on tree seedlings in a semi-arid savanna. J Ecol 97:430-439

van Langevelde F, van de Vijver C, Kumar L, van de Koppel J, de Ridder N, van Andel J, Skidmore AK, Hearne JW, Stroosnijder L, Bond WJ, Prins HHT, Rietkerk M (2003) Effects of fire and herbivory on the stability of savanna ecosystems. Ecology 84:337-350

Venter FJ, Scholes RJ, Eckhardt HC (2003) The abiotic template and its associated vegetation pattern. In: Du Toit JT, Rogers KH, Biggs HC (eds) The Kruger Experience. Island Press, Washington, pp 83-129

Waldram MS, Bond WJ, Stock WD (2008) Ecological engineering by a mega-grazer: White Rhino impacts on a South African savanna. Ecosystems 11:101-112

Wilson SD, Tilman D (1993) Plant competition and resource availability in response to disturbance and fertilization. Ecology 74:599-611

Witkowski ETF, O'Connor TG (1996) Topo-edaphic, floristic and physiognomic gradients of woody plants in a semi-arid African savanna woodland. Vegetatio 124:9-23

Ydenberg RC, Prins HHT (1981) Spring grazing and the manipulation of food quality by barnacle geese. J Appl Ecol 18:443-453

Zambatis N, Zacharias PJK, Morris CD, Derry JF (2006) Reevaluation of the disc pasture meter calibration for the Kruger National Park, South Africa. Afr J Range For Sci 23:85-97 